\title{
Bioanalytical method for quantification of Solifenacin in rat plasma by LC-MS/MS and its application to pharmacokinetic study
}

Srinivasa Babu Puttagunta', Rihana Parveen Shaik ${ }^{1,2^{*}}$, Chandrasekhar Kothapalli Bannoth ${ }^{2}$, Bala Sekhara Reddy Challa ${ }^{3}$ and Bahlul Zayed Sh Awen ${ }^{4}$

\begin{abstract}
Background: Solifenacin succinate is a competitive muscarinic acetylcholine receptor antagonist used in the treatment of overactive bladder with or without urge incontinence.

Methods: Liquid chromatography-tandem mass spectrometry method was used for quantification of Solifenacin (SF) in rat plasma. Solifenacin-d5 (SFD5) used as an internal standard. Chromatographic separation was performed Gemini-NX C18, $50 \times 4.6$ mm, $5 \mu \mathrm{m}, 110 \AA$ column. Mobile phase composed of $5 \mathrm{mM}$ Ammonium formate, $\mathrm{pH}$ 3.0: methanol $(20: 80 \mathrm{v} / \mathrm{v})$, with $0.4 \mathrm{~mL} / \mathrm{min}$ flow-rate. Drug and IS were extracted by Liquid- liquid extraction method. SF and SFD5 were detected with proton adducts at $\mathrm{m} / \mathrm{z} 363.2^{\oplus 193.2}$ and $368.2^{\oplus} 198.2$ in multiple reaction monitoring (MRM) positive mode respectively. The method was validated with the correlation coefficients of ( $r 2) \geq 0.9975$ over a linear concentration range of $0.1-100.0 \mathrm{ng} / \mathrm{mL}$.
\end{abstract}

Results: This method demonstrated intra and inter-day precision within 1.09 to 4.84 and 1.75 to $7.68 \%$ and accuracy within 101.21 to 106.67 and 97.94 to $104.79 \%$ for SF.

Conclusions: This method is successfully applied in the Pharmacokinetic study of rat plasma.

Keywords: Mass spectrometry; Solifenacin; Rat plasma; Pharmacokinetics

\section{Background}

Solifenacin succinate is a competitive muscarinic acetylcholine receptor antagonist used in the treatment of overactive bladder with or without urge incontinence. Chemically, it is 1-azabicyclo[2.2.2] oct-8-yl(1S)-1-phenyl3,4-dihydro-1H-isoquinoline-2-carboxylate.

The molecular formula of Solifenacin succinate is $\mathrm{C} 23 \mathrm{H} 26 \mathrm{~N} 2 \mathrm{O} 2$ with its molecular weight 362.46 . Solifenacin is extensively metabolized in the liver. One pharmacologically active metabolite (4R-hydroxy Solifenacin) occurs at low concentrations and three pharmacologically inactive metabolites ( $\mathrm{N}$-glucuronide and the $\mathrm{N}$-oxide and 4Rhydroxy-N-oxide of Solifenacin) in human plasma after oral dosing. After oral administration of vesicare to healthy

\footnotetext{
* Correspondence: rihanaparveen@gmail.com

${ }^{1}$ Vignan Colllege of pharmacy, Vadlamudi, Guntur, Andhra Pradesh 522213, India 2Jawaharlal Nehru Technological University, Anantapur, Andhra Pradesh 515002, India

Full list of author information is available at the end of the article
}

volunteers, peak plasma levels $\left(C_{\max }\right)$ of Solifenacin reached within 3 to $8 \mathrm{~h}$ after administration and at steady state ranged from 32.3 to $62.9 \mathrm{ng} / \mathrm{mL}$ for the 5 and $10 \mathrm{mg}$ vesicare tablets, respectively. The terminal elimination halflife of Solifenacin (SF) is approximately 45 to $68 \mathrm{~h}$. Solifenacin is approximately $98 \%$ (in vivo) bound to human plasma proteins, principally to alpha1-acid glycoprotein (Morales-Olivas and Estan 2010; Doroshyenko and Fuhr 2009; Hoffstetter and Leong 2009; Kuipers et al. 2004; Leone Roberti Maggiore et al. 2012; Uchida et al. 2004; Yamada et al. 2012; Maruyama et al. 2008; Kuipers et al. 2006; Callegari et al. 2011).

Literature survey reveals that quantification of Solifenacin in human plasma (Macek et al. 2010; Mistri et al. 2008), rat plasma (Yanagihara et al. 2007), pharmaceutical compounds (Krishna et al. 2010; Desai et al. 2012; Rami Reddy et al. 2013; Desai et al. 2011), and industrial waste streams (Ann-Marie et al. 2011) were reported. These 
methods were reported by using liquid chromatographyelectrospray ionization-tandem mass spectrometry (LC-MS/ MS) (Macek et al. 2010; Mistri et al. 2008; Ann-Marie et al. 2011), high-performance liquid chromatography (HPLC) (Yanagihara et al. 2007; Krishna et al. 2010; Desai et al. 2012; Rami Reddy et al. 2013), and HPTLC (Desai et al. 2011). Among all, quantification of Solifenacin by LC-MS/MS in biological matrices (Macek et al. 2010; Mistri et al. 2008; Yanagihara et al. 2007) was proved best results.

Macek et al. 2010 reported with the linearity range of 0.47 to $42 \mathrm{ng} / \mathrm{mL}$ and used PPT method for extraction of drug and internal standard (IS). They used $250 \mu \mathrm{L}$ of plasma sample for extraction procedure and obtained good chromatography within 3 min run time. They used Solifenacin $\mathrm{d} 5$ as an internal standard. Mistri et al. (2008) reported with the linearity range of 0.6 to $60 \mathrm{ng} / \mathrm{mL}$ and used liquid-liquid extraction (LLE) method for extraction of drug and IS. They used $500 \mu \mathrm{L}$ of plasma sample for extraction procedure and obtained good chromatography with in $3 \mathrm{~min}$ run time. They used propranolol as an internal standard. (Yanagihara et al. 2007) reported with the linearity range of 2.0 to $2,000.00 \mathrm{ng} / \mathrm{mL}$ and used LLE method for extraction of drug and IS. They used $1,000 \mu \mathrm{L}$ of plasma sample for extraction procedure and obtained good chromatography within 25 min run time. They used $\left((-)-\left[(1 R\right.\right.$ or $\left.1 S), 3 \_R\right]$-quinuclidin-3_-yl 1-benzyl1,2,3,4-tetrahydroisoquinoline-2-carboxylate monohydrochloride as an internal standard.

The reported methods have some drawbacks in terms of large amount of plasma sample usage, lower sensitivity (Macek et al. 2010; Mistri et al. 2008; Yanagihara et al. 2007), long run analysis time, and internal standard usage (Yanagihara et al. 2007). The main goal of the present study is to develop and validate the novel simple, higher sensitive, selective, rapid, rugged, and reproducible bioanalytical method for quantitative determination of SF in rat plasma by LC-MS/MS with a small amount of sample volume. The developed method would be applied in the pharmacokinetic study of rat plasma.

\section{Methods}

\section{Chemicals and reagents}

Solifenacin succinate, Solifenacin d5 hydrochloride obtained from Hetero Drugs, Hyderabad, India (Figure 1). HPLC grade methanol was purchased from Jt. Baker Mallinckrodt Baker, Inc., Phillipsburg, NJ, USA. Formic acid was purchased from S.D. Fine Chemicals, Mumbai, India. Diethyl ether was purchased from Merck Speciality Private Limited, Worli, Mumbai, India. Ultrapure water from Milli-Q system (Millipore, Bedford, MA, USA) was used through the study. All other chemicals in this study were of analytical grade. Rats were obtained from Bioneeds, Bangalore, Karnataka, India.

\section{Instrumentation}

HPLC system (1200 Series Agilent Technologies, Deutschland, Germany) connected with triple quadrupole mass spectrometer instrument (API 4000, Toronto, Canada). Data processing was performed with the Analyst 1.5.1 software package (SCIEX, Framingham, MA 01701, USA). Ionization was performed by electrospray positive mode with unit resolution.

\section{Detection}

Mass parameters were optimized to get the product ions of $\mathrm{m} / \mathrm{z}, 193.2$ and $\mathrm{m} / \mathrm{z}, 198.2$ from its respective precursor ions of SF $[\mathrm{M}+\mathrm{H}]^{+}(\mathrm{m} / z, 363.2)$ and SFD5 $[\mathrm{M}+\mathrm{H}]^{+}(\mathrm{m} / z$, 368.2) with source temperature $500^{\circ} \mathrm{C}$, ion spray voltage $5,500 \mathrm{~V}$, heater gas, nebulizer gas 35 psi each, curtain gas 20 psi, CAD gas 5 psi (all gas channels with nitrogen), source flow rate $400 \mu \mathrm{L} / \mathrm{min}$ without split, entrance potential $10 \mathrm{~V}$, declustering potential $55 \mathrm{~V}$ for analyte and $65 \mathrm{~V}$ for internal standard, collision energy $25 \mathrm{~V}$ for both analyte and internal standard, and collision cell exit potential $13 \mathrm{~V}$ for analyte and $12 \mathrm{~V}$ for internal standard.

\section{Chromatographic conditions}

Chromatography was performed using Gemini-NX C18, $50 \times 4.6 \mathrm{~mm}, 5 \mu \mathrm{m}, 110 \AA$ analytical column at $30^{\circ} \mathrm{C}$, with $5 \mathrm{mM}$ ammonium formate, $\mathrm{pH} 3.0 /$ methanol $(20: 80 v / v)$ as

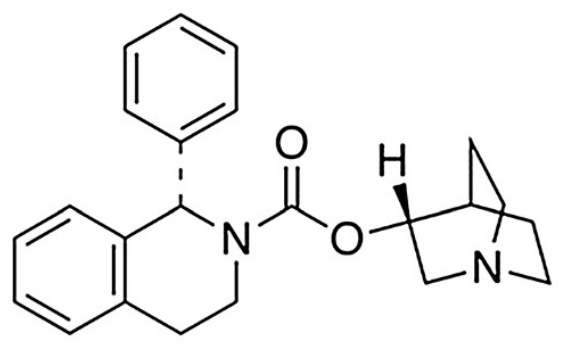

(A) Solifenacin

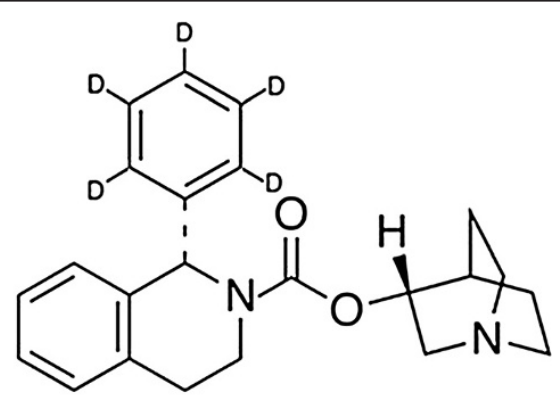

(B) Solifenacin D5

Figure 1 Chemical structures of Solifenacin (A) and Solifenacin d5 (B). 
mobile phase at a flow rate of $0.4 \mathrm{~mL} / \mathrm{min}$. SFD5 was used as an internal standard in terms of chromatography and extractability. The drug and internal standard was eluted at $1.2 \pm 0.2 \mathrm{~min}$ with $2 \mathrm{~min}$ total run time.

\section{Preparation of standards and quality control samples}

Standard stock solutions of SF $(50.0 \mu \mathrm{g} / \mathrm{mL})$ and SFD5 $(50.0 \mu \mathrm{g} / \mathrm{mL})$ was prepared in methanol. The internal standard spiking solution $(50.0 \mathrm{ng} / \mathrm{mL})$ was prepared in water from SFD5 standard stock solution $(50.0 \mu \mathrm{g} / \mathrm{mL})$. Standard stock solutions and internal standard spiking solutions were stored in refrigerator conditions $\left(2^{\circ} \mathrm{C}\right.$ to $\left.8^{\circ} \mathrm{C}\right)$ until analysis. Standard stock solution of SF was added to screened drug-free rat plasma to obtain concentration levels of $0.1,0.2,1.0,5.0,10.0,40.0,60.0,80.0$, and $100.0 \mathrm{ng} / \mathrm{mL}$ for analytical standards and $0.1,0.3,50.0$, $75.0 \mathrm{ng} / \mathrm{mL}$ for quality control (QC) standards and stored in a $-30^{\circ} \mathrm{C}$ freezer until analysis. Respective aqueous standards were prepared in reconstitution solution $(5 \mathrm{mM}$ ammonium formate $\mathrm{pH} 3.0 /$ methanol (20:80) and stored in refrigerator conditions $2^{\circ} \mathrm{C}$ to $8^{\circ} \mathrm{C}$ until analysis.

\section{Sample preparation}

Liquid-liquid extraction was used to isolate drug and IS from rat plasma. For this purpose, $50 \mu \mathrm{L}$ of IS $(40.0 \mathrm{ng} / \mathrm{mL})$ and $100 \mu \mathrm{L}$ of plasma sample (respective concentration) was added into labeled polypropylene tubes and vortexed briefly. Followed by $2.5 \mathrm{~mL}$ of extraction solvent (diethyl ether) was added and vortexed for $10 \mathrm{~min}$. Then, the samples were centrifuged at $4,000 \mathrm{rpm}$ for $10 \mathrm{~min}$ at $20^{\circ} \mathrm{C}$ temperature. Subsequently, the supernatant from each sample was transferred into respective polypropylene tubes. After that, all the samples were kept for evaporation under nitrogen at $40^{\circ} \mathrm{C}$. The dried residue was reconstituted with $1,000 \mu \mathrm{L}$ of reconstitution solution $(5 \mathrm{mM}$ ammonium formate $\mathrm{pH}$ 3.0/methanol (20:80)) and vortexed briefly. Finally, the extracted sample was transferred into auto sampler vials and injected into LC-MS/MS.

\section{Selectivity and specificity}

The selectivity of the method was determined by six different rat blank plasma samples, which were pretreated and analyzed to test the potential interferences of endogenous

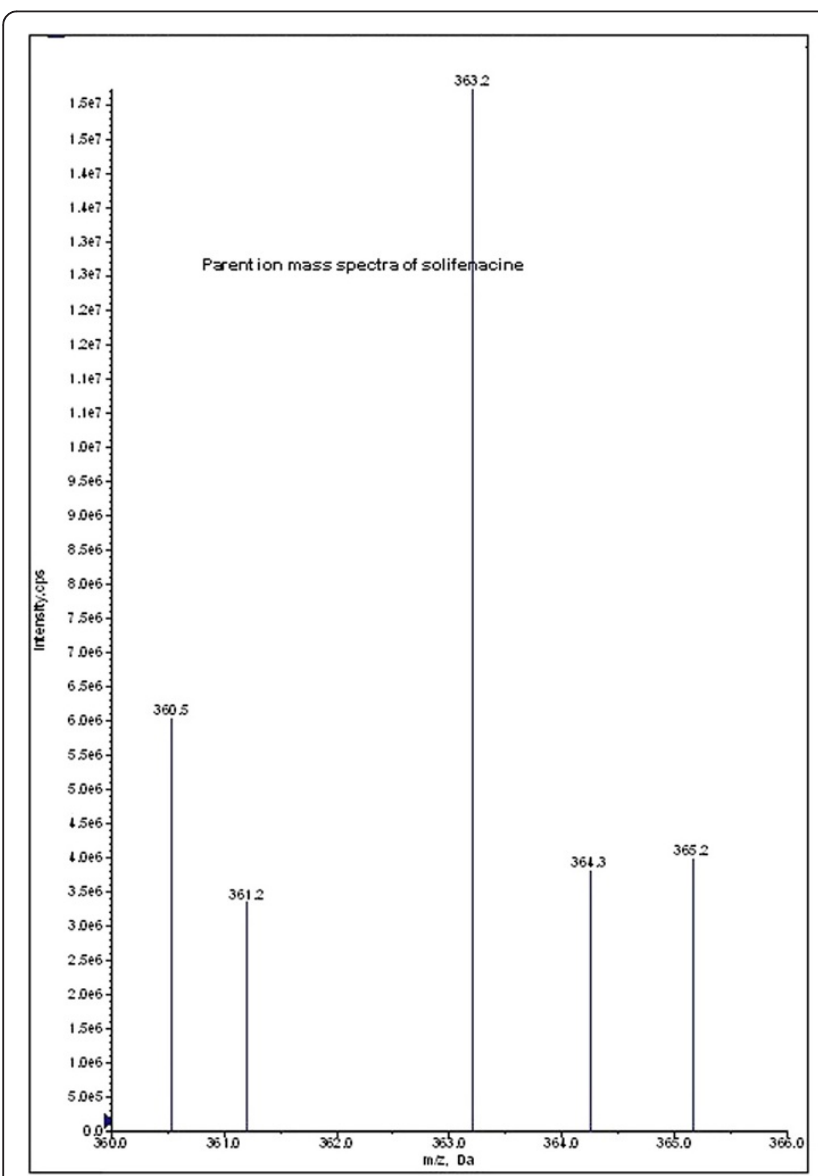

(A)

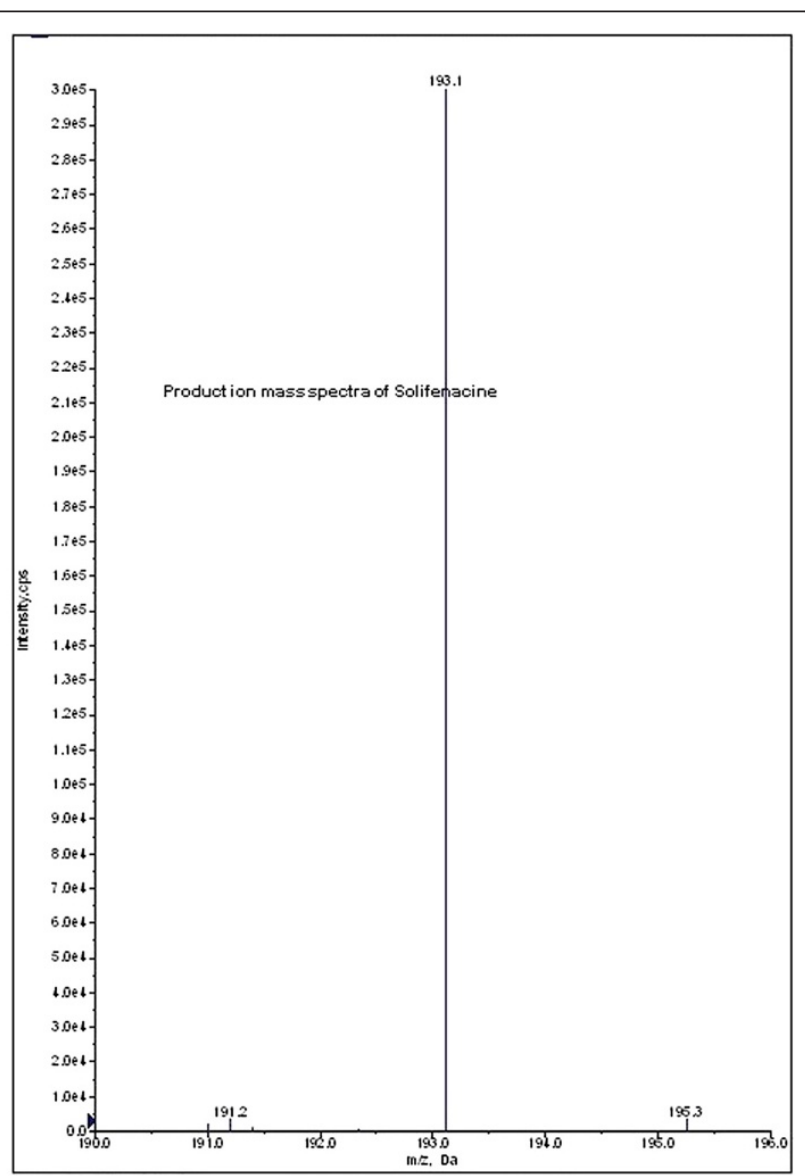

(B)

Figure 2 Mass spectra of (A) Solifenacin parent ion and (B) Solifenacin product ion. 


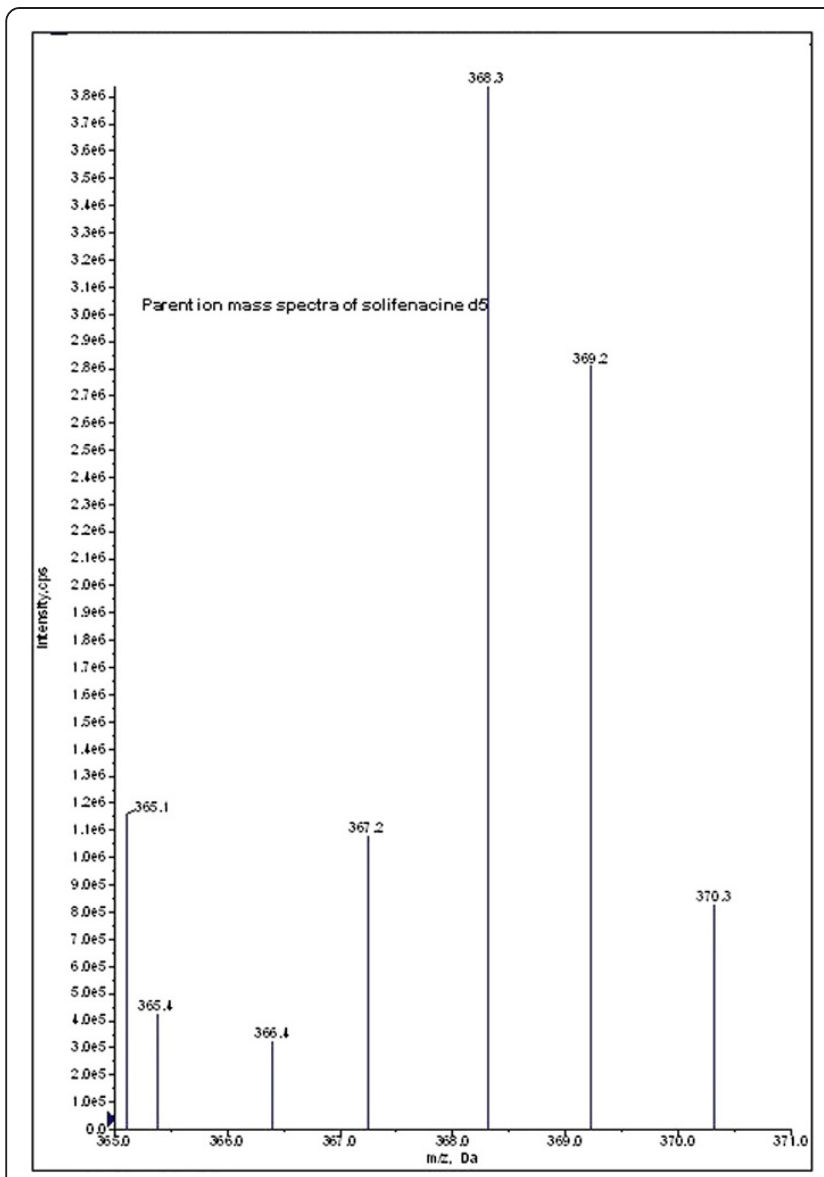

(A)

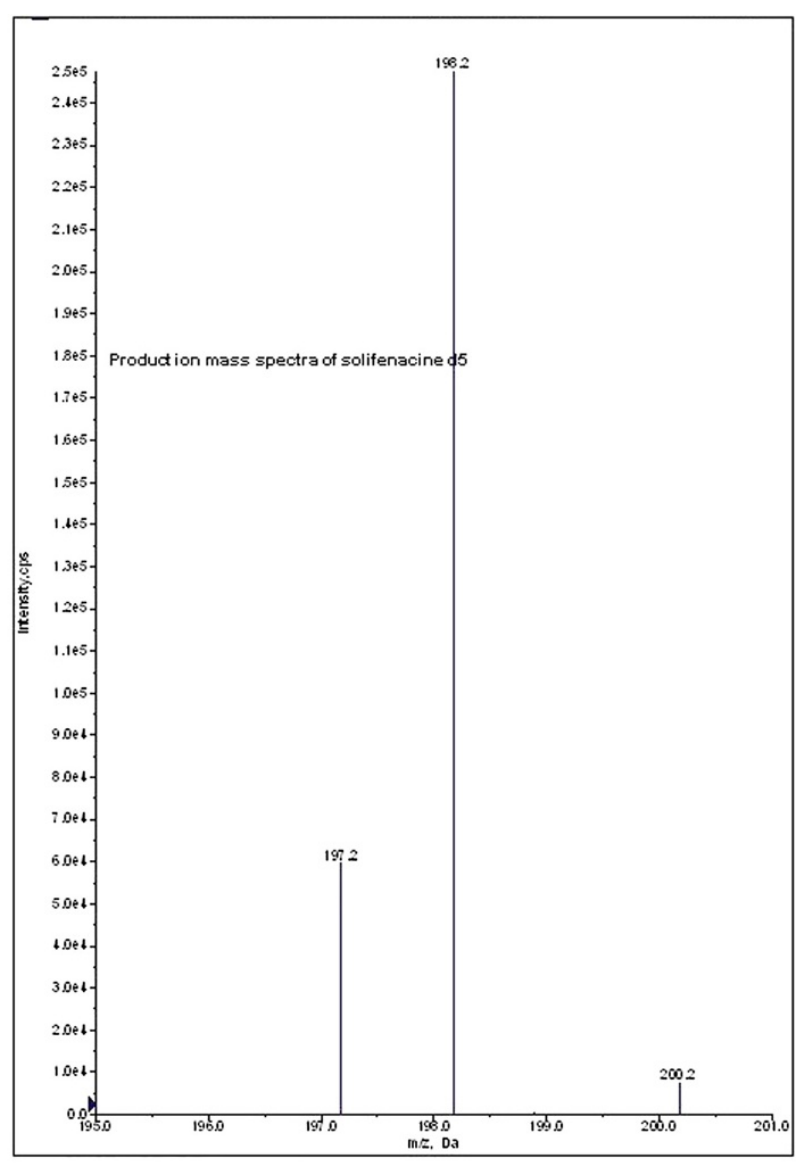

(B)

Figure 3 Mass spectra of (A) Solifenacin d5 parent ion and (B) Solifenacin d5 product ion.

compounds co-eluting with analyte and IS. Chromatographic peaks of analyte and IS were identified based on their retention times and multiple reaction monitoring (MRM) responses. The peak area of SF at the respective retention time in blank samples should not be more than $20 \%$ of the mean peak area of limit of quantification (LOQ) of SF. Similarly, the peak area of SFD5 at the respective retention time in blank samples should not be more than $5 \%$ of the mean peak area of LOQ of SFD5.

\section{Recovery}

The extraction recovery of SF and SFD5 from rat plasma was determined by analyzing quality control samples. Recovery at three concentrations $(1.5,25.0$, and $35.0 \mathrm{ng} / \mathrm{mL}$ ) was determined by comparing peak areas obtained from the plasma sample and the standard solution spiked with the blank plasma residue. A recovery of more than $85 \%$ was considered adequate to obtain required recovery.

\section{Limit of detection and limit of quantification}

The limit of detection (LOD) is a parameter that provides the lowest concentration in a sample that can be detected from background noise but not quantitated. LOD was determined using the signal-to-noise ratio $(\mathrm{S} / \mathrm{N})$ of $3: 1$ by comparing test results from samples with known concentrations of analytes with blank samples.

The LOQ is defined as the lowest concentration of analyte that can be determined with acceptable precision and accuracy. The LOQ was found by analyzing a set of mobile phase and plasma standards with a known concentration of SF.

\section{Matrix effect}

To predict the variability of matrix effects in samples from individual subjects, matrix effect was quantified by determining the matrix factor, which was calculated as follows:

$$
\text { Matrix factor }=\frac{\text { Peak response ratio in presence of extracted matrix (post extracted) }}{\text { Peak response ratio in aqueous standards }}
$$


Six lots of blank biological matrices were extracted each in triplicates and postspiked with the aqueous standard at the low and high QC level and compared with aqueous standards of same concentration. The overall precision of the matrix factor is expressed as coefficient of variation (\%CV) and \%CV should be $<15 \%$.

\section{Calibration curve, precision, and accuracy}

The calibration curve was constructed using values ranging from 0.1 to $100.0 \mathrm{ng} / \mathrm{mL}$ of SF in rat plasma. Calibration curve was obtained by linear model with weighted $1 / \mathrm{x}^{2}$ regression analysis. The ratio of SF/SFD5 peak area was plotted against the ratio of SF concentration in $\mathrm{ng} / \mathrm{mL}$. Calibration curve standard samples and quality control samples were prepared in replicates $(n=$ 6) for analysis. Precision and accuracy for the backcalculated concentrations of the calibration points, should be within $\leq 15$ and $\pm 15 \%$ of their nominal values. However, for LLOQ, the precision and accuracy should be within $\leq 20$ and $\pm 20 \%$.

Stability (freeze - thaw, auto sampler, bench top, long-term) of SF in plasma

Low-quality control and high-quality control samples $(n=$ 6) were retrieved from a deep freezer after three freeze- thaw cycles according to the clinical protocol. Samples were stored at $-30^{\circ} \mathrm{C}$ in three cycles of 24,36 and $48 \mathrm{~h}$. In addition, the long-term stability of SF in quality control samples was also evaluated by analysis after 45 days of storage at $-30^{\circ} \mathrm{C}$. Autosampler stability was studied following 61.5-h storage period in the autosampler tray with control concentrations. Bench top stability was studied for 25-h period with control concentrations. Stability samples were processed and extracted along with the freshly spiked calibration curve standards. The precision and accuracy for the stability samples must be $\leq 15$ and $\pm 15 \%$, respectively, of their nominal concentrations.

\section{Application to pharmacokinetic study}

The developed LC-MS/MS method was successfully applied to a pharmacokinetic study by administration of SF to six male Sprague-Dawley rats by oral route using BD syringe attached with oral gavage needle (size 18) at the dose of $4 \mathrm{mg} / 200 \mathrm{~g}$ body weight. Required quantity of test item (4 mg SF) was accurately weighed and transferred to a mortar and triturated with $2 \%(w / w)$ Tween 80 using a pestle to make a smooth paste. Then, $0.5 \%$ $(w / w)$ carboxymethyl cellulose (CMC) was gradually added and suspended to make a required concentration (1 $\mathrm{mg} / \mathrm{mL}$ of SF). The final suspension was kept under

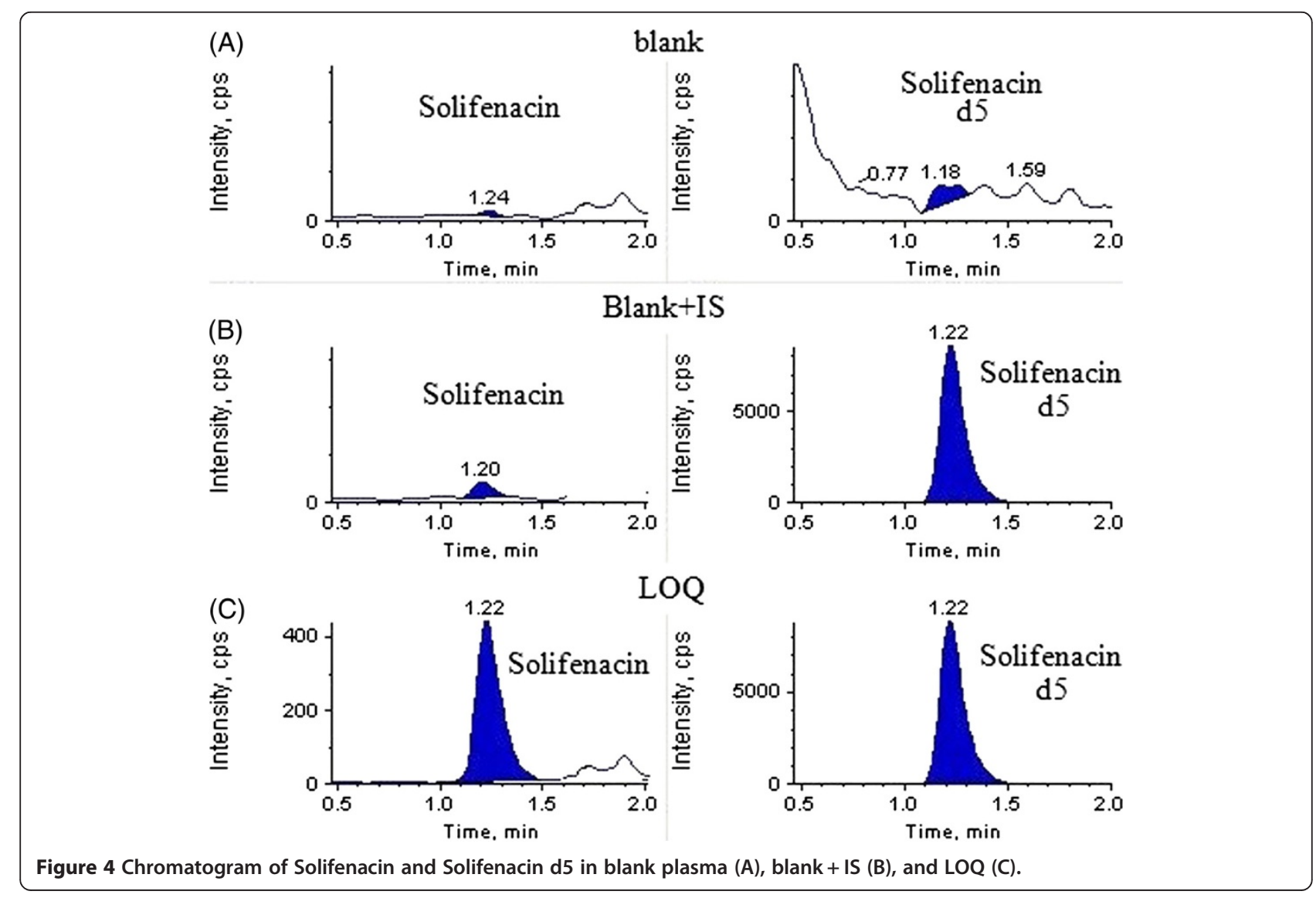


Table 1 Calibration curves details

\begin{tabular}{lcccc}
\hline $\begin{array}{l}\text { Spiked plasma } \\
\text { concentration } \\
(\mathbf{n g} / \mathbf{m L})\end{array}$ & $\begin{array}{c}\text { Mean concentration } \\
(\mathbf{n g} / \mathbf{m L}) \pm \text { S.D. }\end{array}$ & S.D. & $\begin{array}{c}(\mathrm{CV} \%) \\
(\boldsymbol{n}=\mathbf{5})\end{array}$ & Accuracy (\%) \\
\hline 0.10 & 0.11 & 0.01 & 6.46 & 110.40 \\
0.20 & 0.19 & 0.01 & 4.78 & 95.40 \\
1.00 & 0.97 & 0.01 & 1.33 & 97.10 \\
5.00 & 5.12 & 0.16 & 3.17 & 102.32 \\
10.00 & 10.10 & 0.09 & 0.94 & 101.00 \\
40.00 & 39.68 & 0.39 & 0.98 & 99.19 \\
60.00 & 59.89 & 0.63 & 1.05 & 99.82 \\
80.00 & 80.74 & 0.68 & 0.84 & 100.92 \\
100.00 & 99.55 & 0.35 & 0.35 & 99.55 \\
\hline
\end{tabular}

continuous stirring till the dose administration. Approximately, $0.2 \mathrm{~mL}$ of blood samples from each anesthetized (isoflurane) rat at pre-determined time intervals was collected from the retro-orbital plexus using a capillary tube into pre-labeled eppendorf tubes containing $10 \%$ of $\mathrm{K}_{2}$ EDTA anticoagulant $(20 \mu \mathrm{L})$. The time intervals for the sample collection were 0 (predose), $0.5,1,2,3,4,5$, $6,8,16,24,36,48$, and $72 \mathrm{~h}$ (postdose). The total blood volume collected from each rat was approximately 1.9 to $2.2 \mathrm{~mL}$ which does not exceed the maximal recommended blood volume of $20 \%$ (2.0 mL for a $200 \mathrm{~g}$ body weight rat). Plasma was obtained by centrifuging blood samples at 3,000 rpm for $10 \mathrm{~min}$. The obtained plasma samples were transferred into pre-labeled microcentrifuge tubes and stored at $-30^{\circ} \mathrm{C}$. All the samples were analyzed by the developed method. Pharmacokinetic parameters were calculated by non-compartmental analysis by using Win Nonlin ${ }^{\odot} 5.1$ software. Concentrations obtained from the above bio-analytical method were compiled (FDA 2002; FDA 2003).

\section{Results and discussion}

Method development and method validation

LC-MS/MS has been used as one of the most powerful analytical tools in clinical pharmacokinetics for its selectivity, sensitivity, and reproducibility. The goal of this work is to develop and validate a simple, sensitive, rapid, rugged, and reproducible assay method for the quantitative determination of SF from rat plasma samples.
Chromatographic conditions, especially the composition and nature of the mobile phase, usage of different columns, and different extraction methods such as solid phase, precipitation, and liquid-liquid extraction methods were optimized through several trials to achieve the best resolution and increase the signal of SF and SFD5. The MS optimization was performed by direct infusion of solutions of both SF and SFD5into the ESI source of the mass spectrometer. The critical parameters in the ESI source that include the needle (ESI) voltage, capillary voltage, source temperature, and other parameters such as nebulizer gas, heater gas, and desolvation gasses were optimized to obtain a better spray shape, resulting in better ionization of the protonated ionic SF and SFD5 molecules. Product ion spectrum for SF and SFD5 yielded high-abundance fragment ions of $m / z 193.2$ and $m / z 198.2$, respectively (Figures 2 and 3). After mass spectrometer parameters optimized, chromatographic conditions such as mobile phase optimization, column optimization, and extraction method optimization was performed to obtain a fast and selective LC method.

A good separation and elution were achieved using $5 \mathrm{mM}$ ammonium formate, $\mathrm{pH} 3.0 /$ methanol $(20: 80 v / v)$ as the mobile phase at a flow rate of $0.4 \mathrm{~mL} / \mathrm{min}$ and injection volume of $5 \mu \mathrm{L}$. Gemini-NX C18, $50 \times 4.6 \mathrm{~mm}$, $5 \mu \mathrm{m}, 110 \AA$ column, and liquid-liquid extraction method was optimized for the best chromatography (Figure 4).

The developed method was validated over a linear concentration range 0.1 to $100.0 \mathrm{ng} / \mathrm{ml}$. The validation parameters that include selectivity and specificity, LOD and LOQ, matrix effect, precision and accuracy, recovery, stability (freeze - thaw, auto sampler, bench top, long-term) were evaluated under validation section (FDA 2001).

\section{Selectivity and specificity}

The analysis of SF and SFD5 using MRM function was highly selective with no interfering compounds. Chromatograms obtained from plasma spiked with $\mathrm{SF}(0.1 \mathrm{ng} / \mathrm{mL})$ and SFD5 $(50.0 \mathrm{ng} / \mathrm{mL})$ are shown in Figure 4.

\section{Limit of detection and quantification}

The limit of detection was used to determine the instrument detection levels for SF even at low concentrations.

Table 2 Precision and accuracy

\begin{tabular}{|c|c|c|c|c|c|c|}
\hline \multirow{2}{*}{$\begin{array}{l}\text { Spiked plasma } \\
\text { con (ng/mL) }\end{array}$} & \multicolumn{3}{|c|}{ Intraday } & \multicolumn{3}{|c|}{ Interday } \\
\hline & $\begin{array}{l}\text { Concentration measured }(n=6) \\
(\mathrm{ng} / \mathrm{mL})(\text { mean } \pm \text { S.D) }\end{array}$ & (CV \%) & Accuracy (\%) & $\begin{array}{c}\text { Concentration measured } \\
(n=30)(\mathrm{ng} / \mathrm{mL})(\text { mean } \pm \text { S.D. })\end{array}$ & (CV \%) & Accuracy (\%) \\
\hline 0.10 & $0.11 \pm 0.01$ & 4.84 & 106.67 & $0.10 \pm 0.01$ & 7.68 & 98.53 \\
\hline 0.30 & $0.32 \pm 0.01$ & 2.58 & 105.56 & $0.29 \pm 0.04$ & 3.60 & 97.94 \\
\hline 50.00 & $50.61 \pm 0.55$ & 1.09 & 101.21 & $50.84 \pm 0.75$ & 1.48 & 101.67 \\
\hline 75.00 & $79.20 \pm 1.18$ & 1.49 & 105.60 & $78.59 \pm 1.38$ & 1.75 & 104.79 \\
\hline
\end{tabular}


Five microliters of a $0.5-\mathrm{pg} / \mathrm{mL}$ solution was injected, and estimated LOD was $3.2 \mathrm{fg}$ with $\mathrm{S} / \mathrm{N}$ values $\geq 3$ to 5 . The limit of quantification for this method was proven as the lowest concentration of the calibration curve which was proven as $0.1 \mathrm{ng} / \mathrm{ml}$.

\section{Matrix effect}

Six lots of blank biological matrices were extracted each in triplicates and postspiked with the aqueous standard at the mid-QC level and compared with neat standards of the same concentration in alternate injections. The overall precision of the matrix factor is 3.45 for Solifenacin. There was no ion suppression and ion enhancement effect observed due to IS and analyte at respective retention time.

\section{Precision and accuracy}

Calibration curves were plotted as the peak area ratio (SF/SFD5) versus (SF) concentration. Precision and accuracy of calibration curve standards and quality control standards are represented in Tables 1 and 2.

Stability (freeze - thaw, auto sampler, bench top, long-term) Quantification of the SF in plasma subjected to three freeze-thaw cycles $\left(-30^{\circ} \mathrm{C}\right.$ to room temperature), autosampler, room temperature (benchtop), and long-term stability details was shown in Table 3.

\section{Recovery}

The recovery following the sample preparation using liquid-liquid extraction with diethyl ether was calculated by comparing the peak area of SF in plasma samples with the peak area of solvent samples and was estimated at control levels of SF. The recovery of SF was determined at three different concentrations; $1.5,25.0$, and $50.0 \mathrm{ng} / \mathrm{mL}$ were found as $82.05 \%, 80.94 \%$, and $83.33 \%$, respectively. The overall average recovery of SF and SFD5 were found to be $82.11 \%$ and $78.86 \%$, respectively.

Table 3 Stability of the samples

\begin{tabular}{lcccc}
\hline Stability & $\begin{array}{c}\text { Spiked plasma } \\
\text { concentration } \\
(\mathbf{n g} / \mathbf{m L})\end{array}$ & $\begin{array}{c}\text { Concentration } \\
\text { measured }(\mathbf{n g} / \mathbf{m L})\end{array}$ & $\begin{array}{c}\text { (CV \%) } \\
(\mathbf{m}=\mathbf{6})\end{array}$ \\
\hline Room temperature & 0.30 & 0.32 & 0.01 & 3.54 \\
stability (25.0 h) & 75.00 & 77.30 & 1.28 & 1.66 \\
Processed sample & 0.30 & 0.30 & 0.01 & 2.08 \\
stability (61.5 h) & 75.00 & 78.83 & 0.67 & 0.84 \\
& 0.30 & 0.32 & 0.02 & 6.08 \\
Long term stability & 75.00 & 71.93 & 2.90 & 4.03 \\
(45 days) & 0.30 & 0.32 & 0.01 & 3.51 \\
& 75.00 & 77.65 & 0.59 & 0.76 \\
Freeze-thaw stability & cycle 3, 48 h) & & &
\end{tabular}

Table 4 Mean pharmacokinetic parameters of Solifenacin in rat plasma after oral administration of $4 \mathrm{mg} / 200 \mathrm{~g}$ male rat

\begin{tabular}{lc}
\hline Pharmacokinetic & $\begin{array}{c}\text { Solifenacin } \\
\text { values }\end{array}$ \\
\hline Parameter & $1,029.81$ \\
\hline$C_{\text {max }}(\mathrm{ng} / \mathrm{mL})$ & 17.98 \\
$A \cup C_{0-\infty}(\mathrm{ng} \cdot \mathrm{h} / \mathrm{mL})$ & $1,540.77$ \\
$K_{\mathrm{el}}(\mathrm{h} / 1)$ & 0.01433 \\
$T_{\max }(\mathrm{h})$ & 18 \\
$T_{1 / 2}(\mathrm{~h})$ & 48.37 \\
\hline$A U C_{0}$ &
\end{tabular}

$\mathrm{AUC}_{0-\infty}$ area under the curve extrapolated to infinity; $\mathrm{AUC}_{0-t}$, area under the curve up to the last sampling time; $C_{\max }$, the maximum plasma concentration; $T_{\max }$ the time to reach peak concentration; $K_{\mathrm{e}}$, the apparent elimination rate constant.

\section{Pharmacokinetics and statistical analysis}

The validated method has been successfully applied to quantify SF concentrations into a single dose $(4 \mathrm{mg} /$ 200 g body weight of rat) in rats. The pharmacokinetic parameters evaluated were $C_{\max }$ (maximum observed drug concentration during the study), $\mathrm{AUC}_{0}$ to 72 (area under the plasma concentration-time curve measured $24 \mathrm{~h}$, using the trapezoidal rule), $T_{\max }$ (time to observe maximum drug concentration), Kel (apparent first-order terminal rate constant calculated from a semi-log plot of the plasma concentration versus time curve, using the method of least square regression), and $T_{1 / 2}$ (terminal half-life as determined by quotient $0.693 / \mathrm{Kel}$ ). Pharmacokinetic details are shown in Table 4. The mean concentration versus time profile of SF in rat plasma is shown in Figure 5 FDA (2002), FDA (2003) Guidence.

\section{Conclusions}

The method described in this manuscript has been developed and validated over the concentration range of 0.1 to $100.0 \mathrm{ng} / \mathrm{mL}$ in rat plasma. The intrabatch precision was less than $4.84 \%$ and accuracy ranged from $101.21 \%$ to $106.67 \%$. The interbatch precision was less

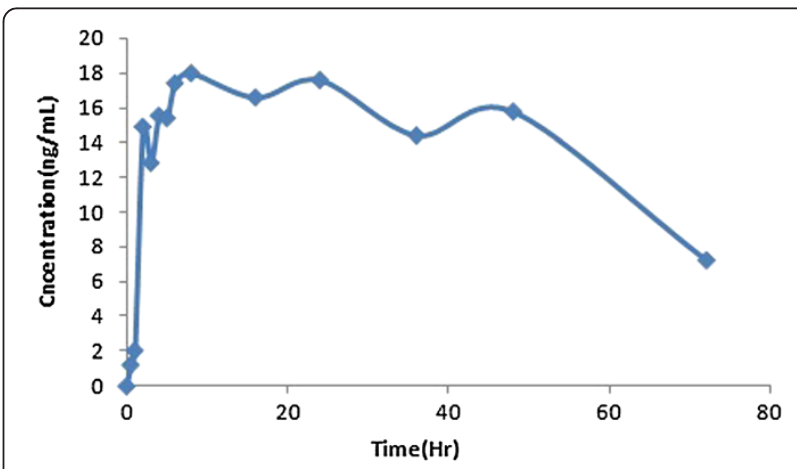

Figure 5 Mean plasma concentration versus time graph of Solifenacin after oral administration of $4 \mathrm{mg}$ dose in $200 \mathrm{~g}$ rat. 
than $7.68 \%$ and accuracy ranged from $97.94 \%$ to $104.79 \%$. The selectivity, sensitivity, precision, and accuracy obtained with this method make it suitable for the purpose of the present study. The simplicity of the method, and using rapid liquid-liquid extraction and sample turnover rate of 2.0 min per sample, makes it an attractive procedure in high-throughput bioanalysis of Solifenacin. The validated method was successfully applied in the pharmacokinetic study of rats by oral administration of $4 \mathrm{mg} / 200 \mathrm{~g}$ in six healthy rats.

\section{Abbreviations}

LC-MS/MS: liquid chromatography-electrospray ionization-tandem mass spectrometry; MRM: multiple reaction monitoring; SF: Solifenacin; SFD5: Solifenacin d5; LLOQ: lower limit of quantification; LOQ: limit of quantification; IS: internal standard; CAD: collisionally activated dissociation.

\section{Competing interests}

The authors declare that they have no competing interests.

\section{Authors' contributions}

SBP carried out the Protocal writing,design of the study, RPS and BRC participated in the Bioanalysis and Pharmacokinetic study, CKB drafted the manuscript and participate the technical guidence of the manuscript. All authors read and approved the final manuscript.

\section{Acknowledgements}

The authors wish to thank the support received from Indian Institute of Chemical Technology (IICT), Hyderabad, India, for providing literature survey and Anthem Bioscience Pvt., Ltd., Banglore, India, for carrying out this research work.

\section{Author details}

${ }^{1}$ Vignan Colllege of pharmacy, Vadlamudi, Guntur, Andhra Pradesh 522213, India. 2Jawaharlal Nehru Technological University, Anantapur, Andhra Pradesh 515002, India. ${ }^{3}$ Vaagdevi College of Pharmacy, Gurazala, Guntur, Andhra Pradesh 522415, India. ${ }^{4}$ Faculty of Pharmacy, Tripoli University, Tripoli 13610, Libya.

Received: 3 January 2014 Accepted: 12 June 2014

Published online: 18 July 2014

\section{References}

Ann-Marie D, Mark C, Michael O, Kieran N, John T, Anne M (2011) A SPE-LC-MS/MS Method for the Detection of Low Concentrations of Pharmaceuticals in Industrial Waste Streams. Anal Lett 44(17):2808-2820

Callegari E, Malhotra B, Bungay PJ, Webster R, Fenner KS, Kempshall S, LaPerle JL, Michel MC, Kay GG (2011) A comprehensive non-clinical evaluation of the CNS penetration potential of antimuscarinic agents for the treatment of overactive bladder. Br J Clin Pharmacol 72(2):235-46

Desai DJ, Patel G, Ruikar D, Jain RA, Rajput SJ (2011) Development and validation of stability-indicating HPTLC method of solifenacin succinate. Asian J Phar Biol Res 1(3):310-316

Desai D, Patel G, Shukla N, Rajput S (2012) Development and validation of stability-indicating HPLC method for solifenacin succinate: Isolation and identification of major base degradation product. Acta Chromatogr 24(3):399-418. http://www.akademiai.com/content/48123rm7t8085531/

Doroshyenko O, Fuhr U (2009) Clinical pharmacokinetics and pharmacodynamics of solifenacin. Clin Pharmacokinet 48(5):281-302

FDA (2001) Guidance for industry: bioanalytical method validation, U.S. Department of Health and Human Services, Food and Drug Administration, Center for Drug Evaluation and Research (CDER), Center for Biologics Evaluation and Research (CBER).

FDA (2002) Guidance for industry: Food- effect bio availability and Fed Bio equivalence studies. U.S. Department of Health and Human services Food and Drug Administration Centre for Drug Evaluation and research (CDER).

FDA (2003) Guidance for industry Bio availability and Fed Bio equivalence Studies for Orally Administered Drug Products-General considerations U.S.
Department of Health and Human services Food and Drug Administration Centre for Drug Evaluation and research (CDER).

Hoffstetter S, Leong FC (2009) Solifenacin succinate for the treatment of overactive bladder. Expert Opin Drug Metab Toxicol 5(3):345-50

Krishna SR, Rao BM, Rao NS (2010) A validated rapid stability-indicating method for the determination of related substances in solifenacin succinate by ultra-fast liquid chromatography. J Chromatogr Sci 48(10):807-10

Kuipers ME, Krauwinkel WJ, Mulder H, Visser N (2004) Solifenacin demonstrates high absolute bioavailability in healthy men. Drugs R D 5(2):73-81

Kuipers M, Smulders R, Krauwinkel W, Hoon T (2006) Open-label study of the safety and pharmacokinetics of solifenacin in subjects with hepatic impairment. J Pharmacol Sci 102(4):405-12

Leone Roberti Maggiore U, Salvatore S, Alessandri F, Remorgida V, Origoni M, Candiani M, Venturini PL, Ferrero S (2012) Pharmacokinetics and toxicity of antimuscarinic drugs for overactive bladder treatment in females. Expert Opin Drug Metab Toxicol 8(11):1387-408

Macek J, Ptacek P, Klima J (2010) Determination of solifenacin in human plasma by liquid chromatography-tandem mass spectrometry. J Chromatogr B Analyt Technol Biomed Life Sci 878(31):3327-30

Maruyama S, Tsukada H, Nishiyama S, Kakiuchi T, Fukumoto D, Oku N, Yamada S (2008) In vivo quantitative autoradiographic analysis of brain muscarinic receptor occupancy by antimuscarinic agents for overactive bladder treatment. J Pharmacol Exp Ther 325(3):774-81

Mistri HN, Jangid AG, Pudage A, Rathod DM, Shrivastav PS (2008) Highly sensitive and rapid LC-ESI-MS/MS method for the simultaneous quantification of uroselective alpha1-blocker, alfuzosin and an antimuscarinic agent, solifenacin in human plasma. J Chromatogr B Analyt Technol Biomed Life Sci 876(2):236-44. http://www.ncbi.n/m.nih.gov/pubmed/19010093

Morales-Olivas FJ, Estan L (2010) Solifenacin pharmacology. Arch Esp Urol 63(1):43-52

Rami Reddy BV, Srinivasa Reddy B, Raman NWSS, Reddy KS, Rambabu C (2013) Development and Validation of a Specific Stability Indicating High Performance Liquid Chromatographic Methods for Related Compounds and Assay of Solifenacin Succinate. J Chem. http://dx.doi.org/10.1155/2013/ 412353

Uchida T, Krauwinkel WJ, Mulder H, Smulders RA (2004) Food does not affect the pharmacokinetics of solifenacin, a new muscarinic receptor antagonist: results of a randomized crossover trial. Br J Clin Pharmacol 58(1):4-7. http:// www.ncbi.nlm.nih.gov/pubmed/15206986

Yamada S, Kuraoka S, Osano A, Ito Y (2012) Characterization of bladder selectivity of antimuscarinic agents on the basis of in vivo drug-receptor binding. Int Neurourol J 16(3):107-15

Yanagihara T, Aoki T, Soeishi Y, Iwatsubo T, Kamimura H (2007) Determination of solifenacin succinate, a novel muscarinic receptor antagonist, and its major metabolite in rat plasma by semi-micro high performance liquid chromatography. J Chromatogr B Analyt Technol Biomed Life Sci 859(2):241-5

doi:10.1186/s40543-014-0035-0

Cite this article as: Puttagunta et al:: Bioanalytical method for quantification of Solifenacin in rat plasma by LC-MS/MS and its application to pharmacokinetic study. Journal of Analytical Science and Technology 2014 5:35.

\section{Submit your manuscript to a SpringerOpen ${ }^{\circ}$ journal and benefit from:}

- Convenient online submission

Rigorous peer review

- Immediate publication on acceptance

- Open access: articles freely available online

- High visibility within the field

- Retaining the copyright to your article

Submit your next manuscript at $>$ springeropen.com 